\title{
Retraction
}

\section{Retracted: A Design of Dual Broadband Antenna in Mobile Communication System}

\section{International Journal of Antennas and Propagation}

Received 15 November 2016; Accepted 15 November 2016

Copyright ( 2016 International Journal of Antennas and Propagation. This is an open access article distributed under the Creative Commons Attribution License, which permits unrestricted use, distribution, and reproduction in any medium, provided the original work is properly cited.

International Journal of Antennas and Propagation has retracted the article titled "A Design of Dual Broadband Antenna in Mobile Communication System" [1]. The article was found to contain a substantial amount of material, without citation, from the following published article: Y. Cui, R. Li and P. Wang, "Novel Dual-Broadband Planar Antenna and Its Array for 2G/3G/LTE Base Stations," in IEEE Transactions on Antennas and Propagation, vol. 61, no. 3, pp. 1132-1139, March 2013. doi: 10.1109/TAP.2012.2229377, where Figures 1, 3, 4, 5, 7 and 9 and Table 1 were reused in Figures 1, 2, 7, 6, 8 and 5 and Table 1 in this article.

\section{References}

[1] J. Zhou, "A design of dual broadband antenna in mobile communication system," International Journal of Antennas and Propagation, vol. 2015, Article ID 975825, 9 pages, 2015 


\title{
A Design of Dual Broadband Antenna in Mobile Communication System
}

\author{
Jianming Zhou \\ School of Information and Electronics, Beijing Institute of Technology, Beijing 100081, China
}

Correspondence should be addressed to Jianming Zhou; zhoujm@bit.edu.cn

Received 30 June 2015; Revised 28 July 2015; Accepted 3 August 2015

Academic Editor: N. Nasimuddin

Copyright (C 2015 Jianming Zhou. This is an open access article distributed under the Creative Commons Attribution License, which permits unrestricted use, distribution, and reproduction in any medium, provided the original work is properly cited.

A design of dual broadband antenna is proposed in this paper; it consists of one low frequency unit and two high frequency units. The low frequency unit consists of a pair of printing vibrators; the high frequency unit consists of a pair of printing oscillators, which is bent at its end, and high frequency unit and low frequency unit are set on the same dielectric substrate. Through adding a parasitic unit on antenna, it can enhance frequency bandwidth without affecting the bandwidth. In the high frequency unit, it adopts gap-coupled microstrip line feeding method in order to get enough bandwidth. Through the test of dual broadband antenna, it can be found that, in the low frequency part, the antenna covers $20 \%$ bandwidth of the total bandwidth, and it covers the frequency from $800 \mathrm{MHz}$ to $980 \mathrm{MHz}$. In the high frequency, the antenna covers $60 \%$ of total bandwidth and its frequency is from $1540 \mathrm{MHz}$ to $2860 \mathrm{MHz}$, so the designed antenna can satisfy the frequency requirements of $2 \mathrm{G} / 3 \mathrm{G} / \mathrm{LTE}$ (4G) communication system.

\section{Introduction}

With the development of mobile communication technology, the different mobile communication systems have different communication frequencies. Now at the present stage, in the $2 \mathrm{G}$ communication system (CDMA800 and GSM900 and GSM1800 and GSM1900), its working frequencies are from $824 \mathrm{MHz}$ to $960 \mathrm{MHz}$ and from $1710 \mathrm{MHz}$ to $1926 \mathrm{MHz}$; the work frequency of $3 \mathrm{G}$ system (TDS-CDMA, WCDMA, and CDMA 2000) is from $1880 \mathrm{MHz}$ to $2170 \mathrm{MHz}$, with the comprehensive promotion of LTE (4G) technology, the frequency of LTE2300/LTE2500 becomes the new demand in the $4 \mathrm{G}$ communication system, and its working frequency band is from $2300 \mathrm{MHz}$ to $2400 \mathrm{MHz} / 2500 \mathrm{MHz}$ and $2690 \mathrm{MHz}$ [14].

Therefore, in the mobile communication system, the antenna should cover frequency band of $824-960 \mathrm{MHz}$ and $1700-2700 \mathrm{MHz}$ at the same time, and the broadband dualfrequency antenna should provide the frequency services for $2 \mathrm{G} / 3 \mathrm{G} / \mathrm{LTE}(4 \mathrm{G})$ system meanwhile. In the paper, it proposes a dual broadband antenna, which is suitable for $2 \mathrm{G} / 3 \mathrm{G} / \mathrm{LTE}$ (4G) wireless communication system. The proposed dualfrequency antenna consists of one low frequency unit and two high frequency units; the low frequency unit consists of a pair of printing vibrators; high frequency unit is made up of a pair of end bending vibrators, and the design can enhance the frequency bandwidth without affecting the bandwidth. In the design, the high frequency unit adopts gap-coupled microstrip line feeding method in order to get broad bandwidth [5-8]. This antenna keeps the ratio of high frequency unit and low frequency with $2: 1$, which can avoid grating lobe of radiation pattern at different high frequencies. Through the test of dual broadband antenna, the results show that the low frequency antenna covers about $20 \%$ relative bandwidth, and it covers the frequency from $800 \mathrm{MHz}$ to $980 \mathrm{MHz}$. In the high frequency part, it has $60 \%$ relative bandwidth, which covers the frequency from $1540 \mathrm{MHz}$ to $2860 \mathrm{MHz}$, and it is enough to satisfy the frequency demands of current 2G/3G/LTE (4G) mobile communication system [9].

\section{Design of Antenna Structure}

The structure of broadband dual-frequency antenna is as shown in Figure 1; the antenna unit consists of one low 


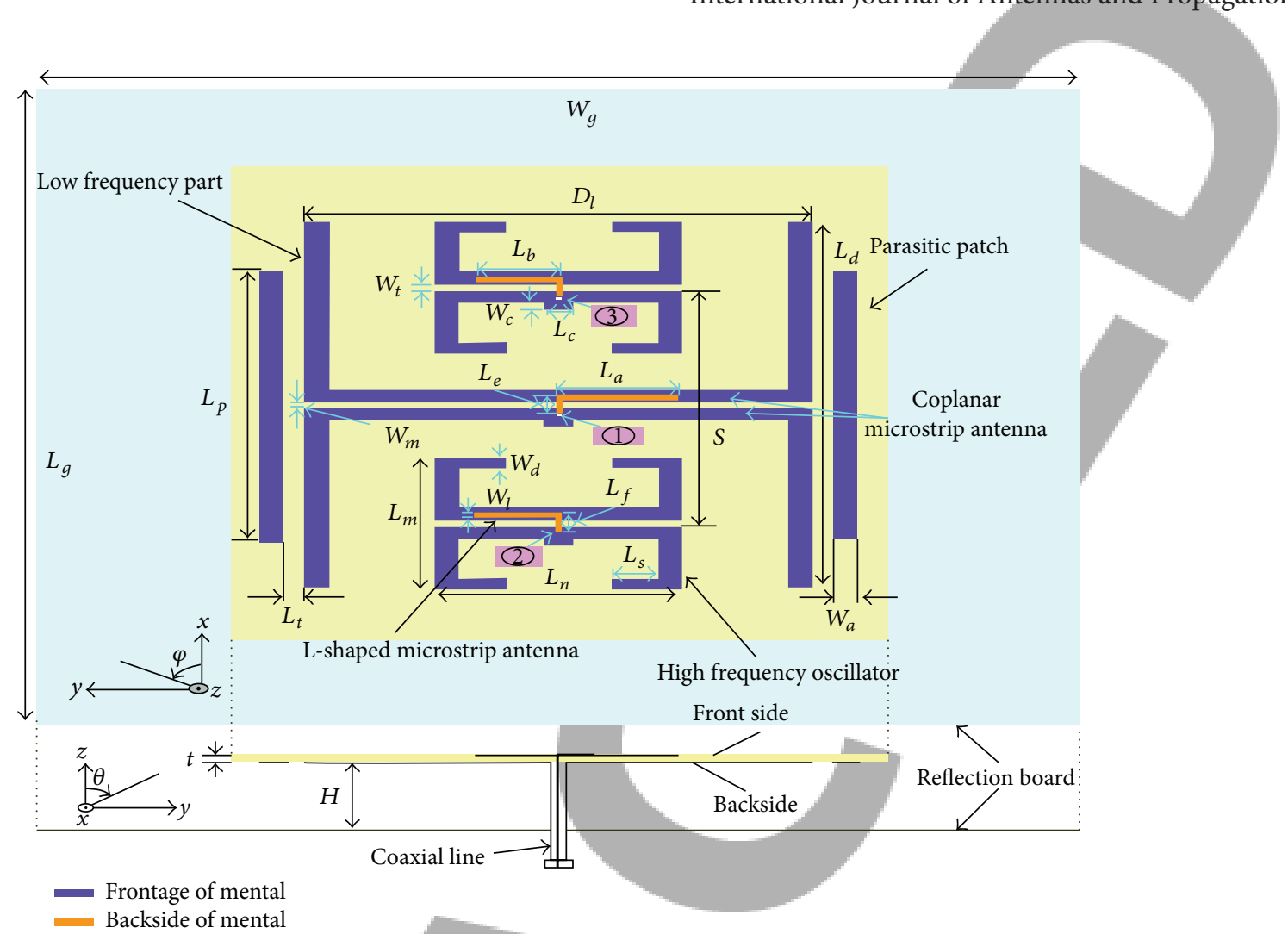

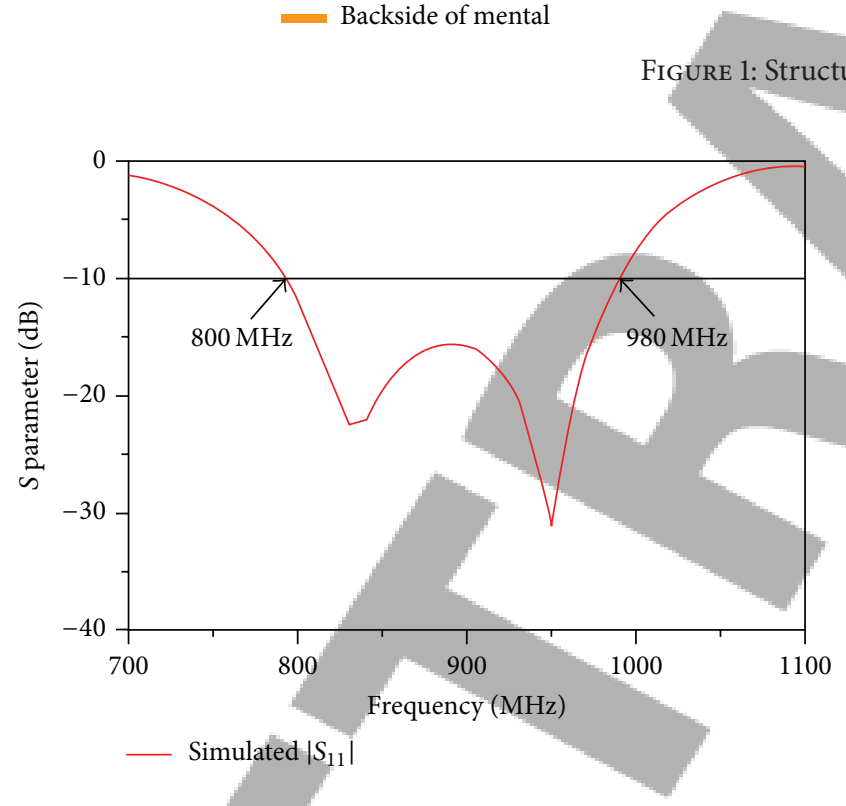

(a) Low frequency part

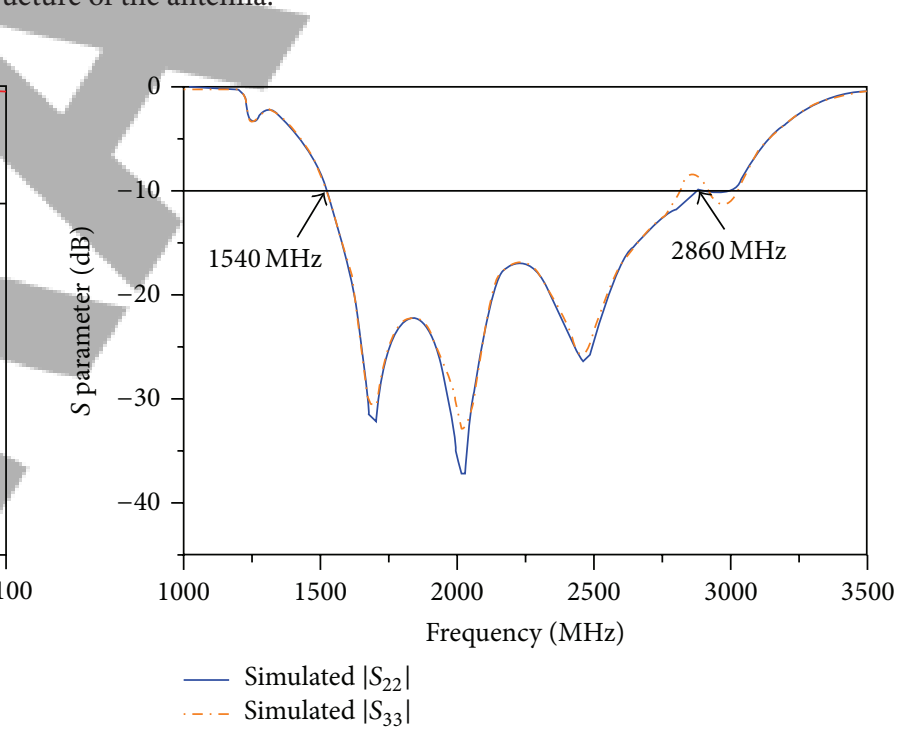

(b) High frequency part

FIGURE 2: Simulation results of the $S$ parameter of the antenna.

frequency unit and two high frequency units. Low frequency unit is a half-wave oscillator, and there is one parasitic patch unit near half-wave oscillator; parasitic patch unit will do help to enhance the effects of low frequency bandwidth. High frequency unit consisted of a pair of folding halfwave oscillators, and half-wave oscillator radiation arms are bent at the end, thus making the high frequency unit smaller. High frequency unit and low frequency unit are both added on the same piece of dielectric substrate of antenna. The distance between two high frequency units is $120 \mathrm{~mm}$; the high frequency unit and low frequency unit of one half-wave oscillator are connected with a parallel microstrip line, and it adopts one $50 \Omega$ L-shaped coupled microstrip line for feeding, and coplanar microstrip line and the L-shaped microstrip lines are adopted to form the gap-coupled microstrip line in the feed structure; 

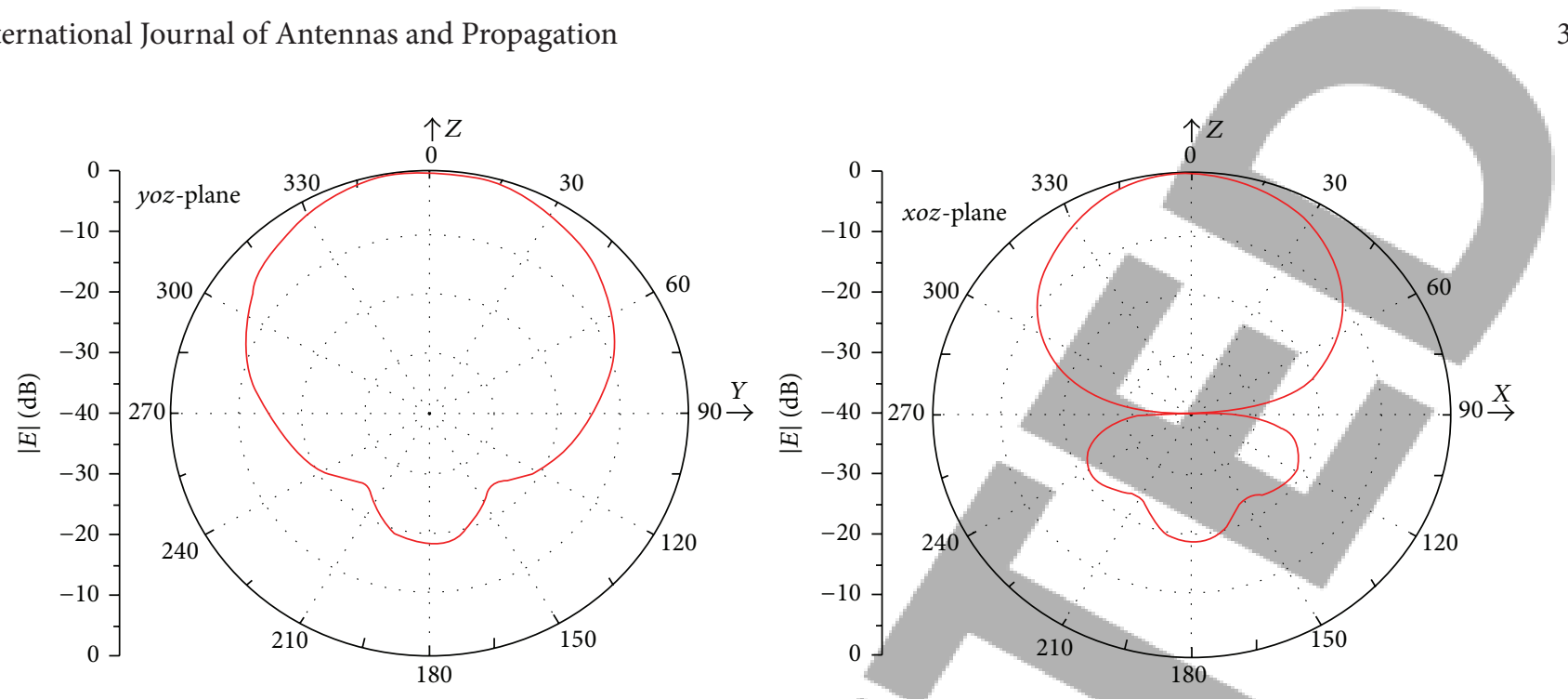

(a) $800 \mathrm{MHz}$
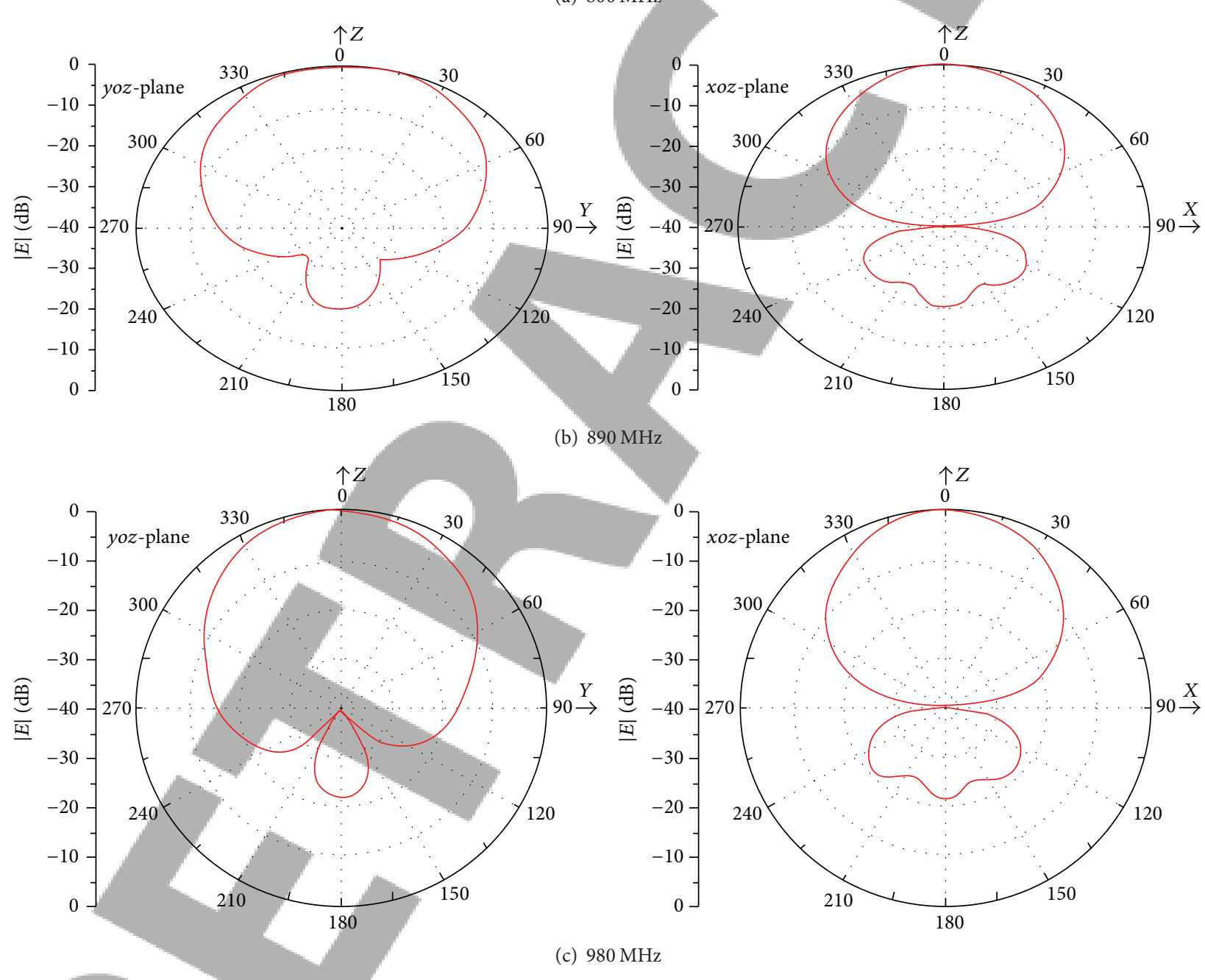

(b) $890 \mathrm{MHz}$

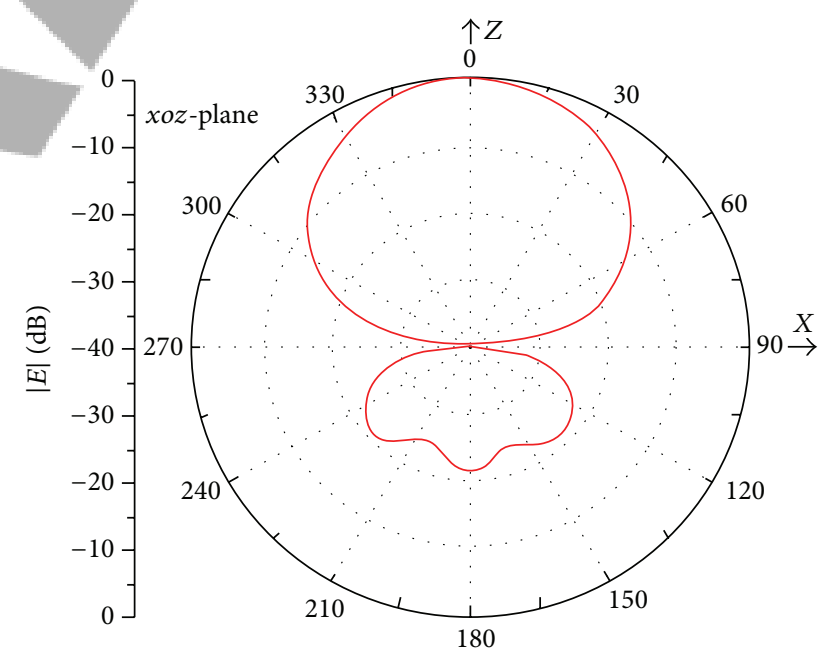

(c) $980 \mathrm{MHz}$

FIGURE 3: Simulation results of the radiation pattern of the antenna in low frequency part.

the coupling feed structure can do help in obtaining broadband of antenna.

In the optimization of the structure of aperture-coupled microstrip line feeding, broadband antenna parameter analysis can be referenced. Antenna is placed on the flat reflection board, in order to realize the performance of directional radiation. Due to the fact that broadband dual-frequency antenna unit has one low frequency unit and two high frequency units, we define the low frequency unit feed port as port 1 and feed port of high frequency unit as port 2 

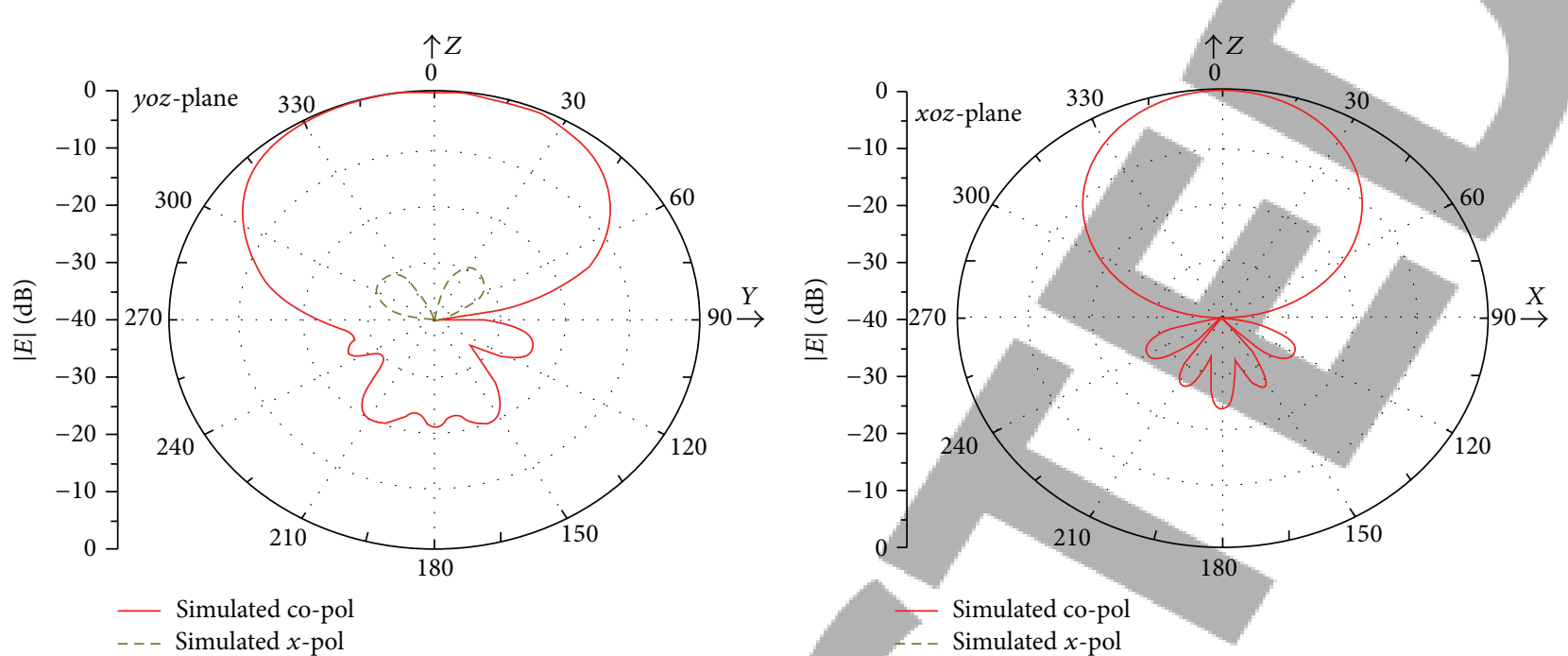

(a) $1700 \mathrm{MHz}$

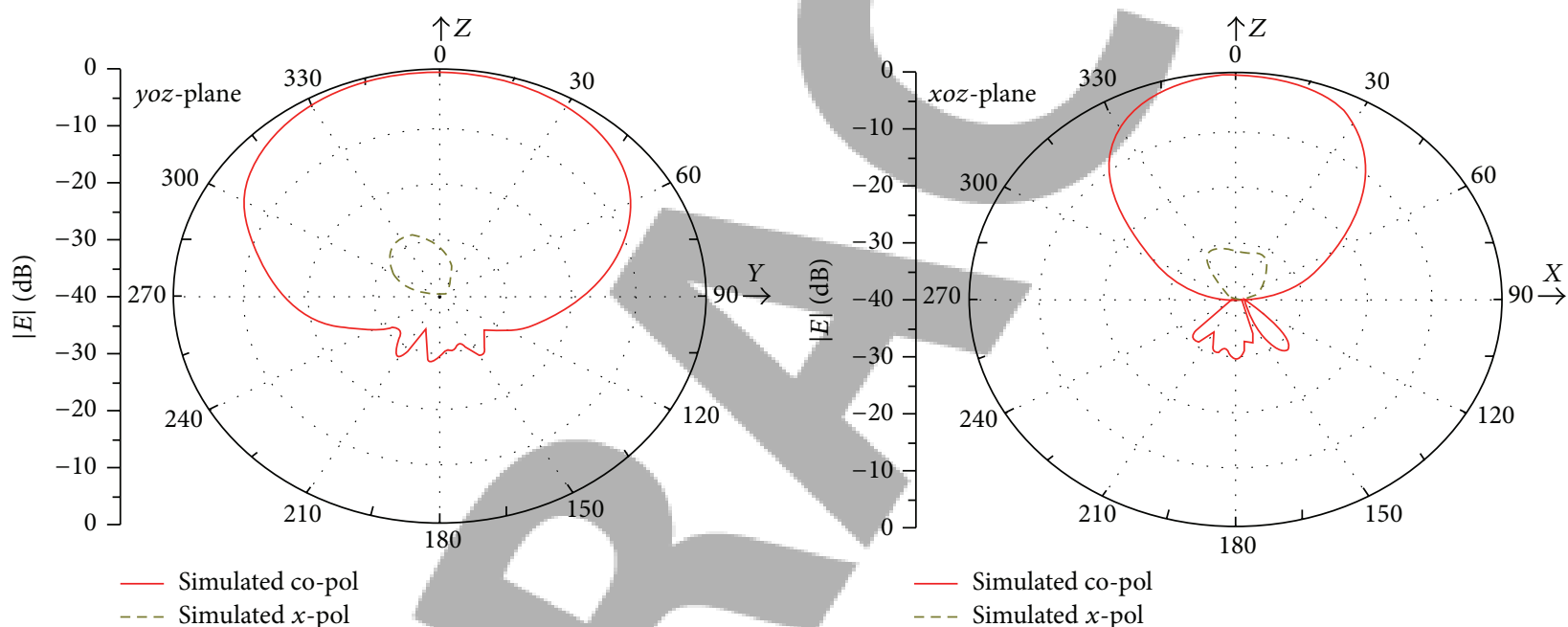

(b) $2200 \mathrm{MHz}$
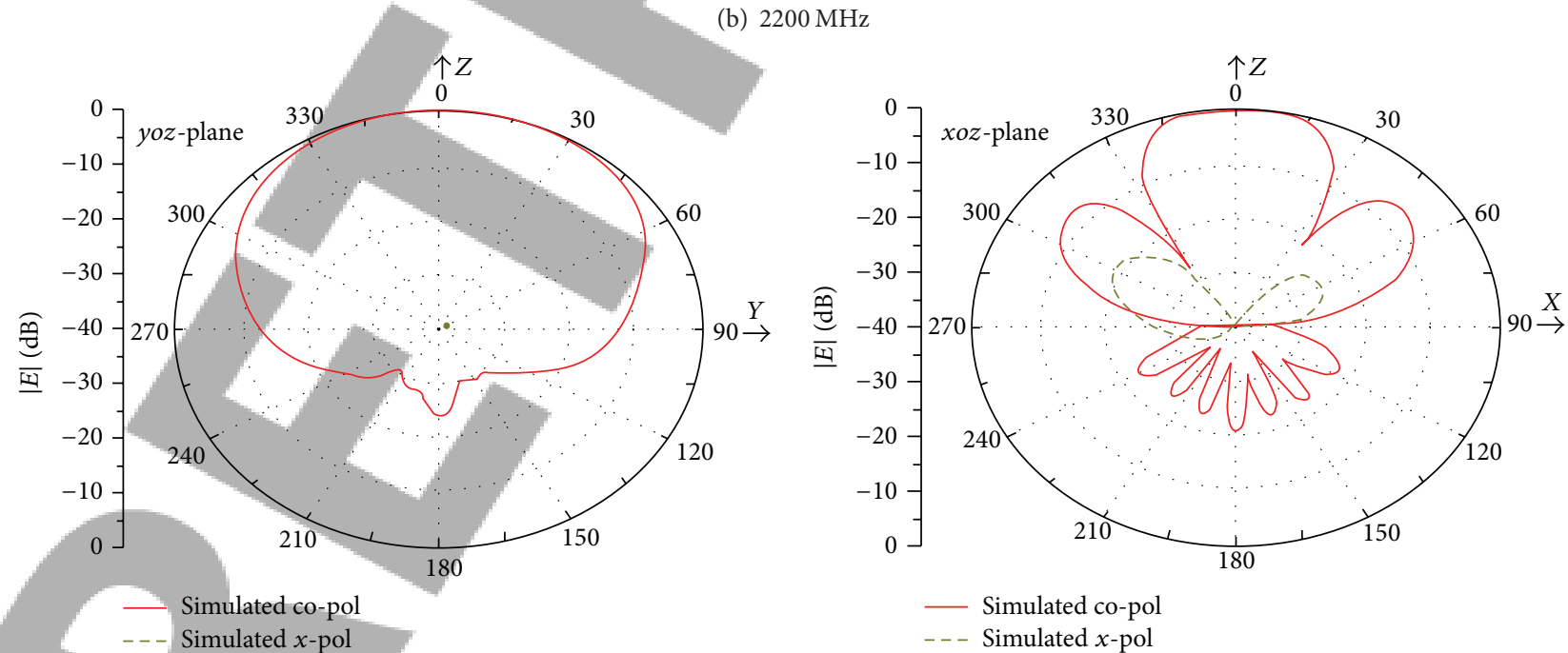

(c) $2700 \mathrm{MHz}$

FIGURE 4: Simulation results of the radiation pattern of the antenna. 


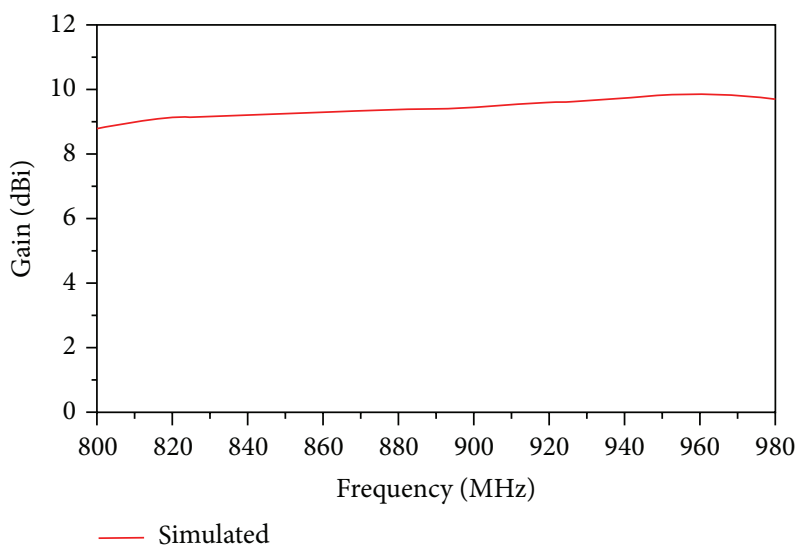

(a) Low frequency part

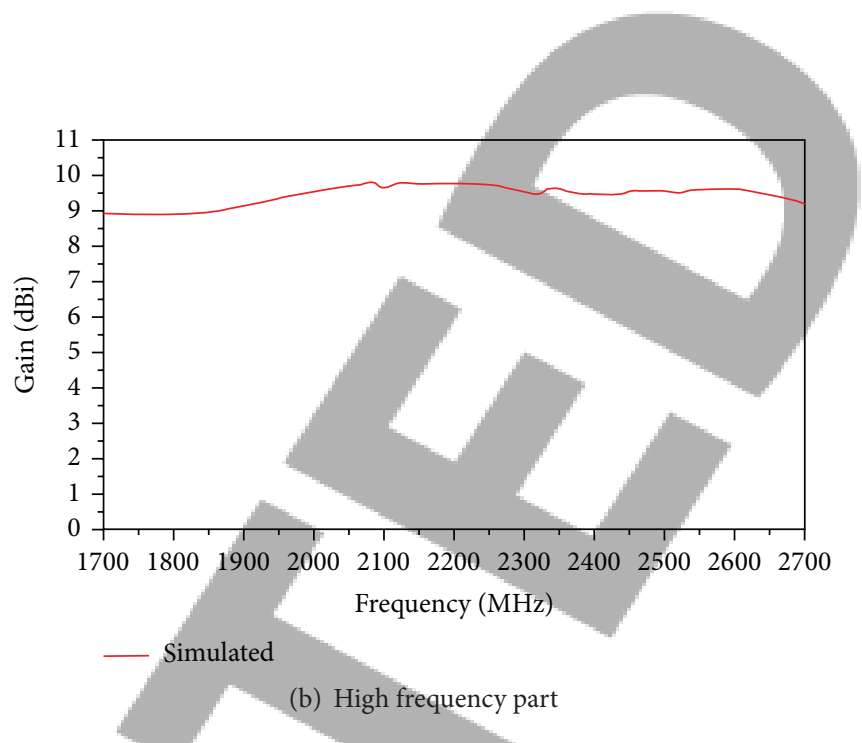

(b) High frequency part

FIGURE 5: The simulation results of the gain of the antenna.

TABLE 1: Size Parameters of Antenna.

\begin{tabular}{lc}
\hline Parameter & Value \\
\hline$L_{a}$ & $25 \mathrm{~mm}$ \\
$L_{b}$ & $17.85 \mathrm{~mm}$ \\
$L_{c}$ & $6 \mathrm{~mm}$ \\
$L_{d}$ & $155 \mathrm{~mm}$ \\
$L_{e}$ & $7.35 \mathrm{~mm}$ \\
$L_{f}$ & $7.95 \mathrm{~mm}$ \\
$L_{g}$ & $360 \mathrm{~mm}$ \\
$t$ & $0.76 \mathrm{~mm}$ \\
$L_{m}$ & $55.6 \mathrm{~mm}$ \\
$L_{n}$ & $50 \mathrm{~mm}$ \\
$L_{p}$ & $115 \mathrm{~mm}$ \\
$L_{s}$ & $9.5 \mathrm{~mm}$ \\
$L_{t}$ & $4 \mathrm{~mm}$ \\
$W_{a}$ & $5 \mathrm{~mm}$ \\
$W_{m}$ & $1.5 \mathrm{~mm}$ \\
$H$ & $45 \mathrm{~mm}$ \\
$W_{t}$ & $2.1 \mathrm{~mm}$ \\
$W_{d}$ & $5 \mathrm{~mm}$ \\
$W_{g}$ & $280 \mathrm{~mm}$ \\
$W_{l}$ & $1.7 \mathrm{~mm}$ \\
$W_{c}$ & $3 \mathrm{~mm}$ \\
$D_{l}$ & $102 \mathrm{~mm}$ \\
$S$ & $100 \mathrm{~mm}$ \\
\hline & \\
& \\
&
\end{tabular}

and port 3, respectively. Through frequency electromagnetic simulation software Ansoft HFSS, we make optimization simulation of the antenna, and the optimal size parameters of antenna are as shown in Table 1.

\section{Simulation}

Simulation results of $S$ parameters of broadband dualfrequency antenna are as shown in Figure 2. In the low frequency part, it can get $20 \%$ of relative bandwidth, and it covers frequency band of $800-980 \mathrm{MHz}$. In the high frequency part, it can get $60 \%$ relative bandwidth, and it covers frequency from $1540 \mathrm{MHz}$ to $2860 \mathrm{MHz}$. The simulation results of antenna direction pattern are as shown in Figure 3, and the direction of radiation pattern is relatively stable on the frequency band from $800 \mathrm{MHz}$ to $980 \mathrm{MHz}$, and there only exist few changes; the simulation results of direction pattern in high frequency are as shown in Figure 4. In frequency band of $1700 \mathrm{MHz}-2700 \mathrm{MHz}$, the radiation pattern is stable.

Simulation results of gain of broadband dual-frequency antenna are as shown in Figure 5. The antenna gain in low frequency band is about $9 \mathrm{dBi}$. At high frequency part, the gain is about $9.5 \mathrm{dBi}$. Simulation results verified that the broadband dual-frequency antenna can achieve the double broadband performance, and it can completely cover frequency band of 824-960 MHz and 1710-2690 MHz.

\section{Experiment and Analysis}

Antenna structure is shown in Figure 1, and the parameters of antenna structure are as shown in Table 1, and the antenna photo is as shown in Figure 6. Broadband plane dualfrequency antenna is fixed on the high frequency substrate produced by Rogers Company whose type is R04350B, its relative permittivity is 3.48 , the dielectric loss angle is 0.0027 , and thickness is $0.76 \mathrm{~mm}$. Antenna is supported by four plastic pillars, and it is fixed on the flat metal reflector with plastic screws.

It adopts three $50 \Omega$ soft coaxial lines whose type is RG316 to feed the low and high frequency units; the inner part of the coaxial line is fixed on L-shaped microstrip line of the substrate, and outer part of the coaxial line is fixed on the backside of the substrate to connect the coplanar microstrip line. In order to test the antenna radiation pattern, it needs to inspire the two high frequency units at the same time. It also should design and make one broadband power splitter to feed two high frequency units. According to line transmission theory, in order to get broadband performance, 


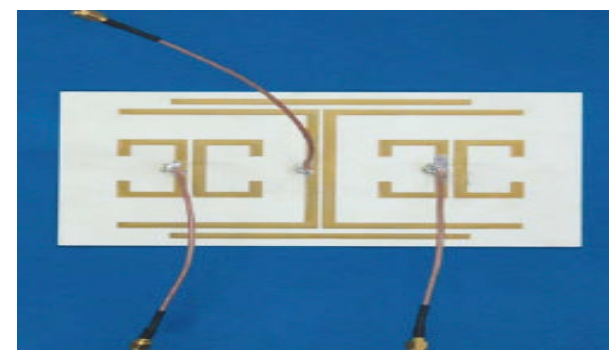

(a) Backside of antenna

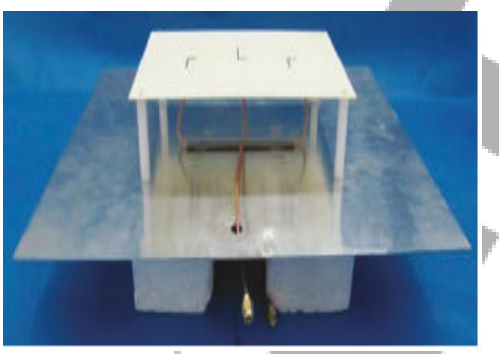

(b) Photo of antenna

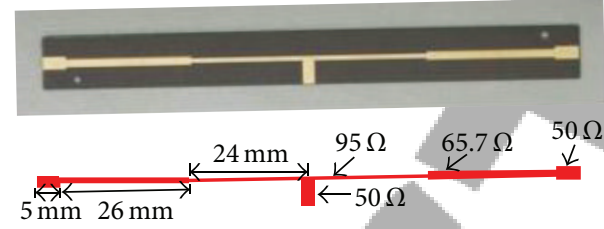

(c) Power divider

Figure 6: Photos of antenna structure.

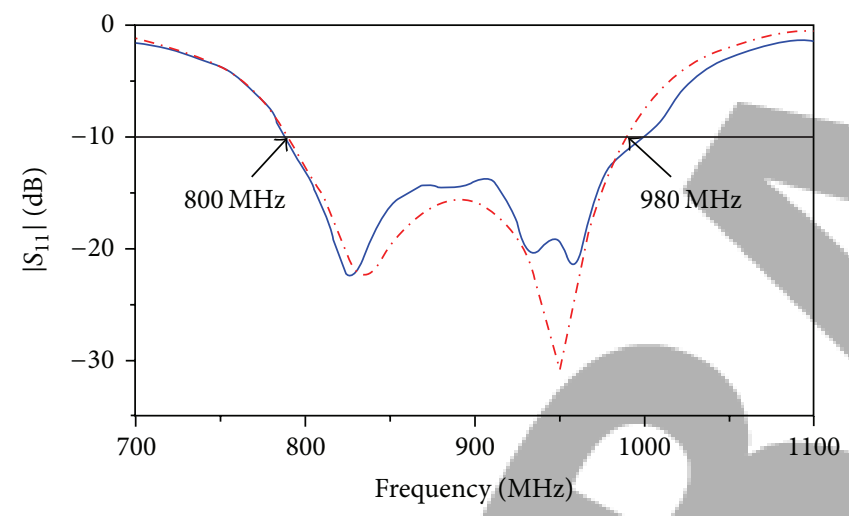

- Measured ...- Simulated

(a) Low frequency part

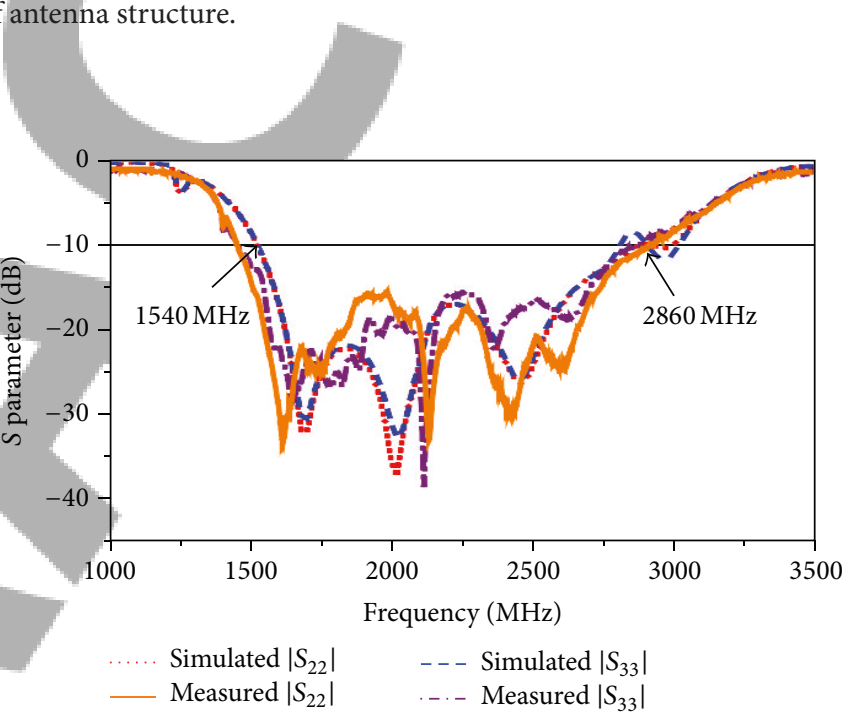

(b) High frequency part

Figure 7: $S$ parameters of the design antenna with three ports.

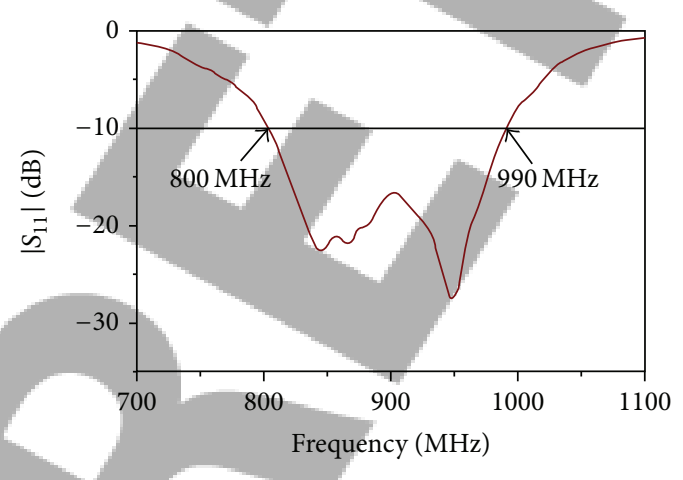

(a) Low frequency part

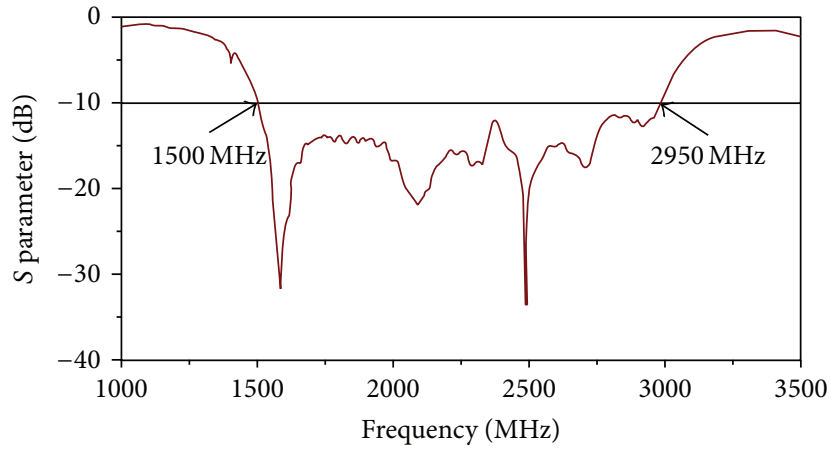

(b) High frequency part

Figure 8: $S$ parameters of the antenna with two ports. 

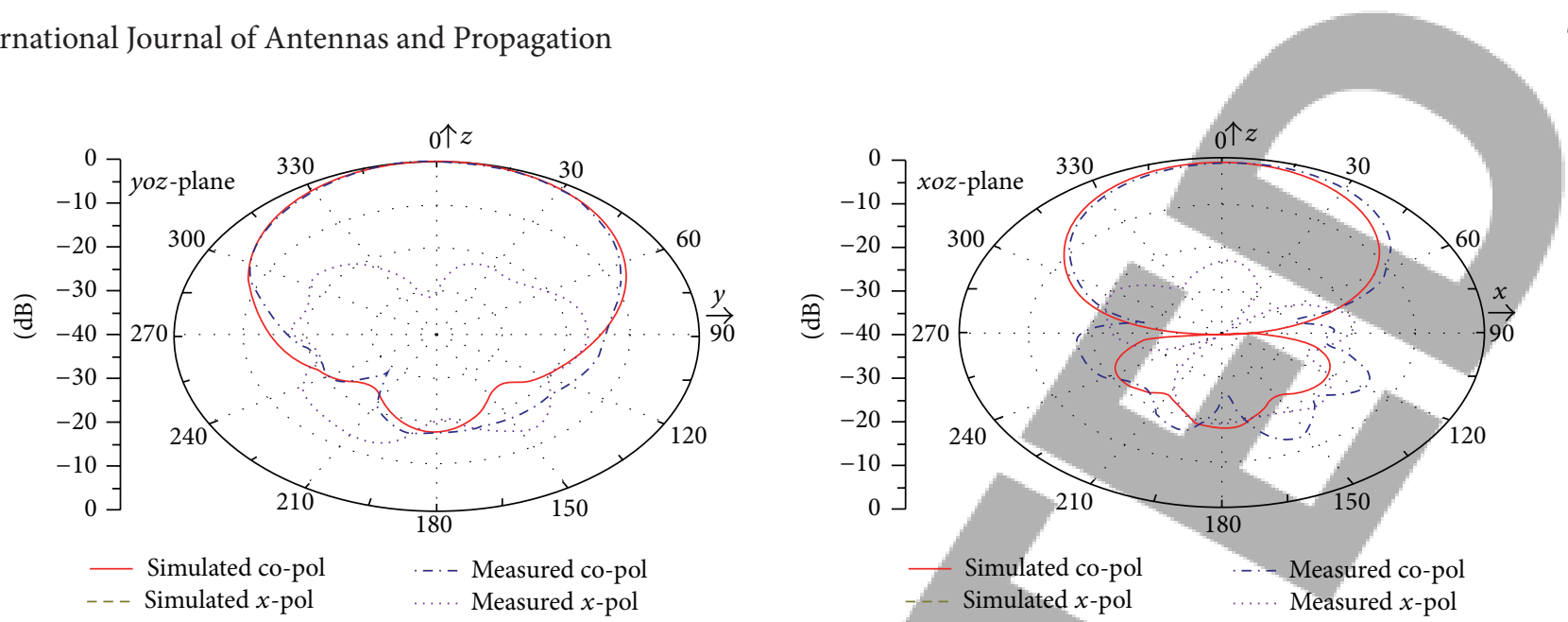

(a) $800 \mathrm{MHz}$
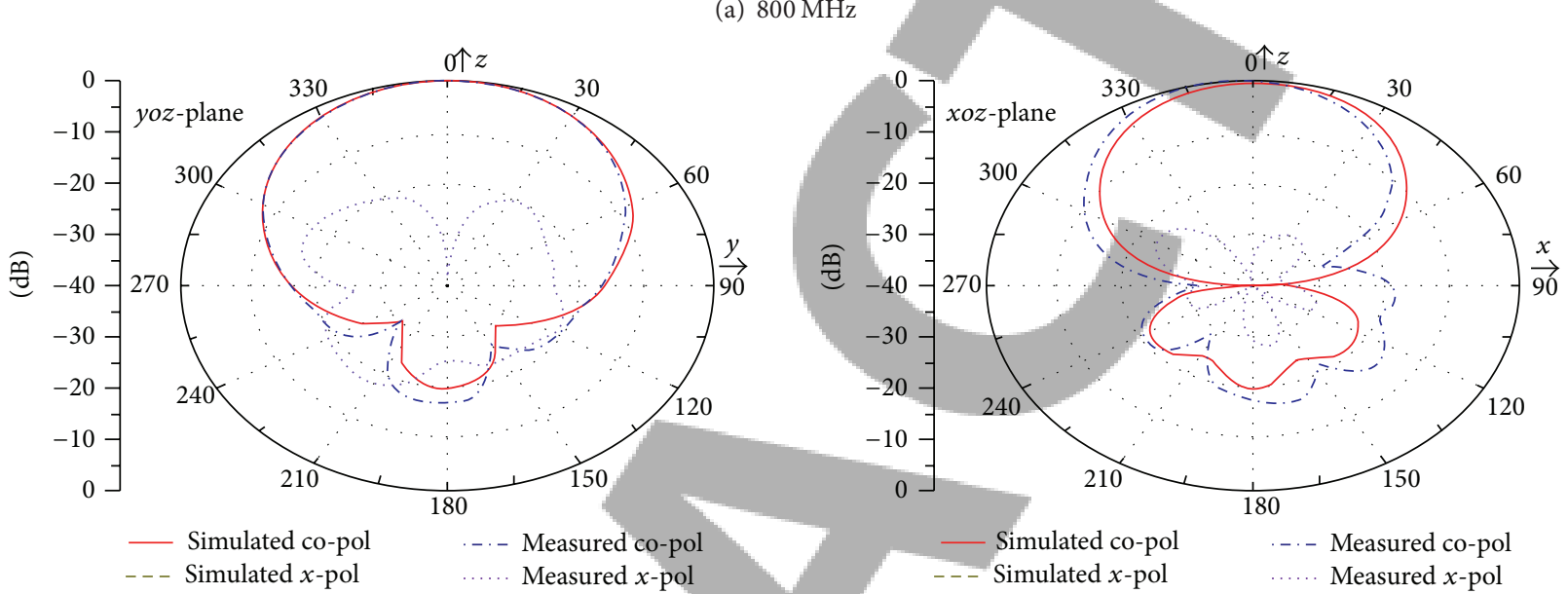

(b) $890 \mathrm{MHz}$

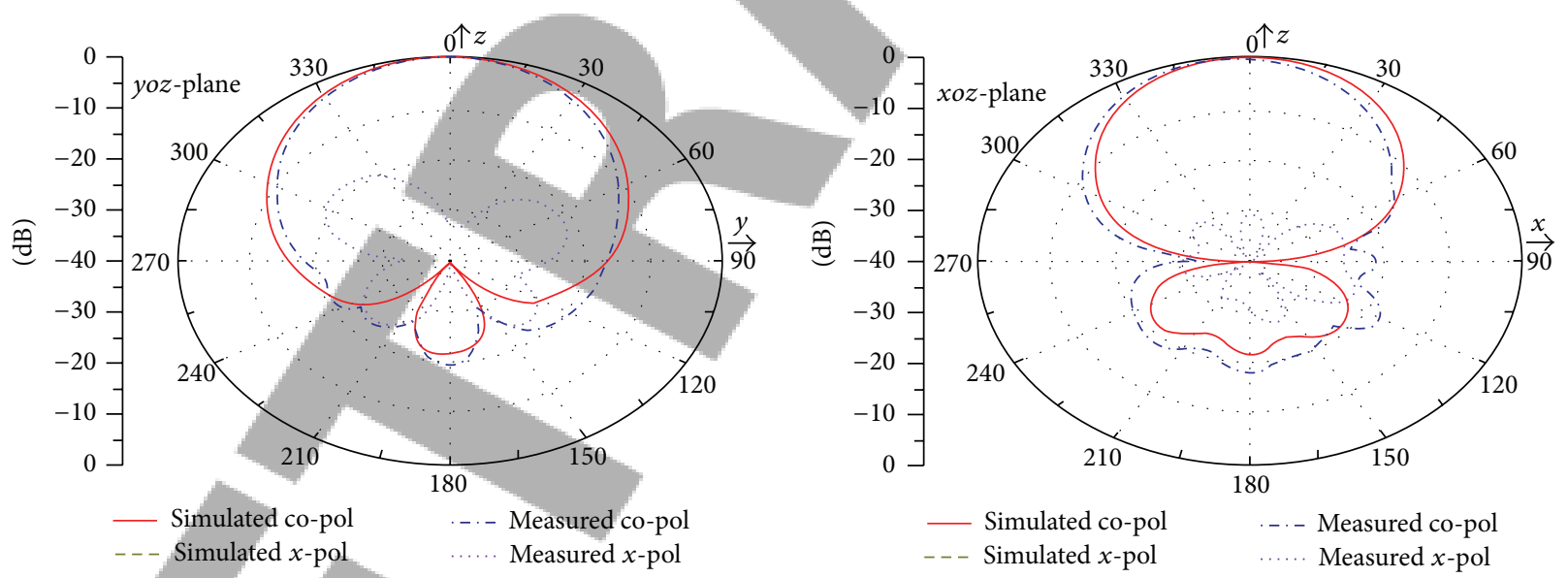

(c) $980 \mathrm{MHz}$

FIGURE 9: Radiation pattern of broadband antenna with two ports.

in the broadband power splitters, we adopt two-quarter impedance converter as shown in Figure 6(c). The broadband dual-frequency antenna is as shown in Figure 6(b), and two high frequency units are connected with the two output ports of the broadband power splitters through the two soft coaxial lines, respectively.

Measurement and simulation results of $S$ parameter of the designed antenna are shown in Figure 7; it can be found that simulation and experimental results are identical with each other. In the measurements, the dual-frequency antenna can get $21 \%$ relative bandwidth among the frequency band $800-$ $980 \mathrm{MHz}$. In high frequency, it gets $60 \%$ relative bandwidth among frequency band $1540-2860 \mathrm{MHz}$.

The measured value of $S$ parameters of the dual-frequency antenna is as shown in Figure 8. In the low frequency part, it gets about $21.2 \%$ of relative bandwidth which covers the 


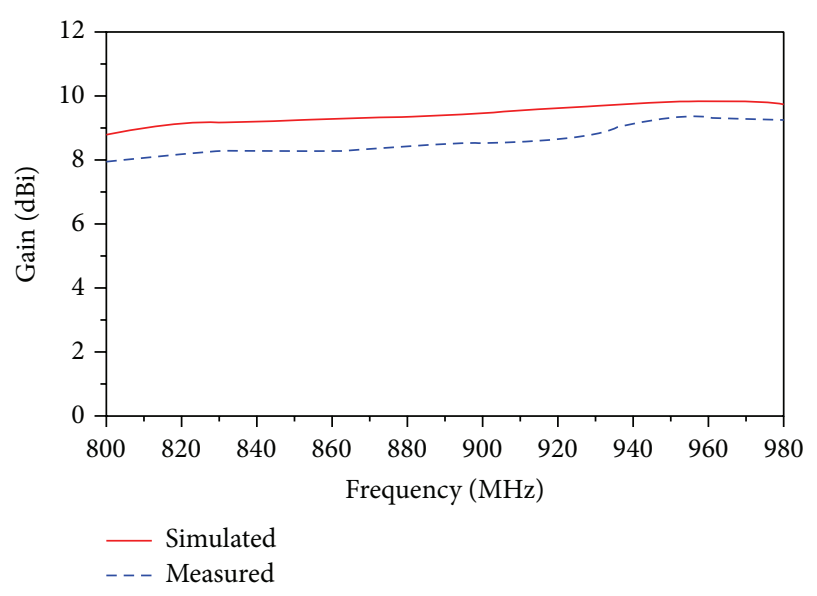

(a) Low frequency part

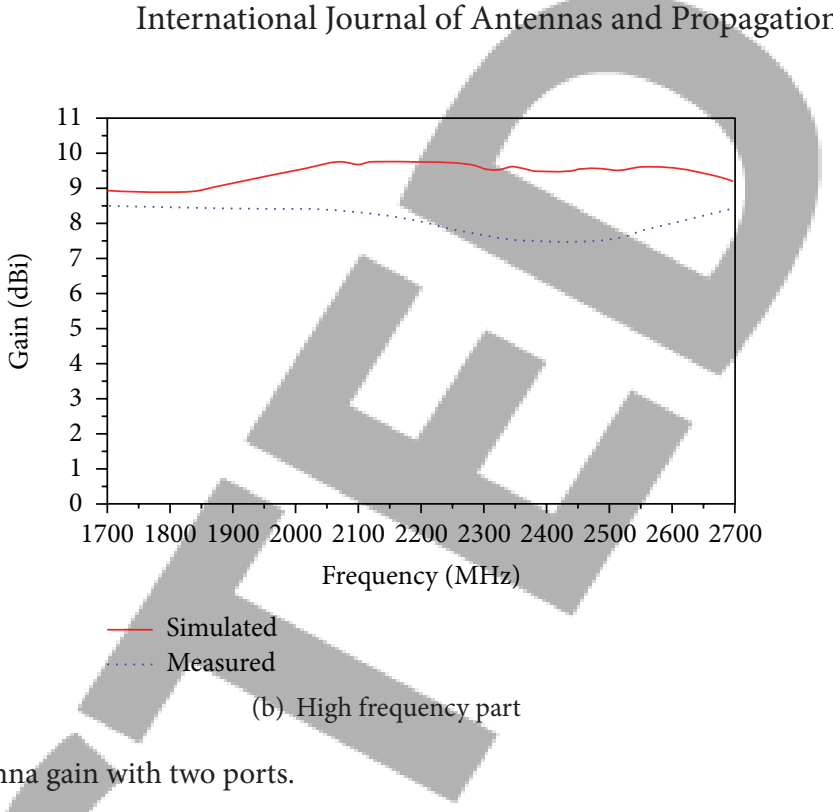

frequency from $800 \mathrm{MHz}$ to $990 \mathrm{MHz}$, and, in the high frequency part, it gets $66 \%$ relative bandwidth which covers the frequency from $1500 \mathrm{MHz}$ to $2950 \mathrm{MHz}$. The amplitude of the measured $S$ parameters of two ports is higher than $S$ parameter $(|S 22|$ or $|S 33|)$ in the three ports. This is because of the introduction of the power dividers. The measured antenna $S$ parameters of three ports results verified the validity of the design and simulation; the measured antenna $S$ parameters of two ports results demonstrate that using the power dividers in the antenna high frequency unit feeding method can also keep the good performance of the bandwidth and guarantee accurate test of antenna radiation performance.

The results of simulation and measured in high frequency and low frequency broadband are as shown in Figure 9. In both high frequency and low frequency bands, the antenna has stable radiation pattern, and the radiation pattern is very similar. The measured horizontal half-power beam width in low frequency band is $60 \pm 5^{\circ}$. In the high frequencies part, the measured half-power beam width is about $90 \pm 5^{\circ}$. In low frequencies, the measured vertical half-power beam width is about $50 \pm 5^{\circ}$, and the measured vertical half-power beam width is $55 \pm 3^{\circ}$ in the high frequencies.

Simulated and measured value of antenna gain is as shown in Figure 10. In both the low frequency and high frequency parts, the gains of antenna are about $8 \mathrm{dBi}$. The measured results are lower than the simulation results, because in the simulation power loss of coaxial line, power splitters and SMA head part are not taken into consideration. Changes of the measured results in both high frequency and low frequency are kept as $1 \mathrm{~dB}$. The gain of broadband dualfrequency antenna can be improved through the arrangement of antenna.

\section{Conclusion}

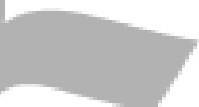

In the paper, a broadband dual-frequency antenna is proposed. It consists of one low frequency unit and two high frequency units; high frequency unit and low frequency unit are parallel half-wave structure; high frequency unit is nested in low frequency unit and forms a compact structure. Through adding parasitic unit near the low frequency unit, it can enhance frequency bandwidth without affecting the bandwidth; high frequency unit adopts gap-coupled microstrip line feeding method, and it does help in obtaining large broadband of antenna.

Experimental results show that the antenna can get $20 \%$ of the relative bandwidth in the low frequency part, which covers frequency band from $780 \mathrm{MHz}$ to $980 \mathrm{MHz}$; in the high frequency, it gets $60 \%$ of the relative bandwidth which covers the frequency from $1470 \mathrm{MHz}$ to $3000 \mathrm{MHz}$. As the ratio between the high frequency and low frequency is $1: 2$, it can avoid the grating lobe of radiation pattern of antenna in high frequencies.

\section{Conflict of Interests}

The author declares that there is no conflict of interests.

\section{References}

[1] C. Wood, "Improved bandwidth of microstrip antennas using parasitic elements," IEE Proceedings H: Microwaves, Optics and Antennas, vol. 127, no. 4, pp. 231-234, 1980.

[2] Y. Liu, K. M. Luk, and H. Yin, "Bowtie patch antenna with electric dipole on a HIS substrate," in Proceedings of the International Conference on Microwave and Millimeter Wave Technology (ICMMT '10), pp. 278-280, Chengdu, China, May 2010.

[3] C.-H. K. Chin, Q. Xue, and H. Wong, "Broadband patch antenna with a folded plate pair as a differential feeding scheme," IEEE Transactions on Antennas and Propagation, vol. 55, no. 9, pp. 2461-2467, 2007.

[4] C. A. Balanis, Antenna Theory: Analysis and Design, Wiley, New York, NY, USA, 2005.

[5] U. K. Revankar and Harishchandra, "Printed dipole radiating elements for broadband and wide scan angle active phased array," in Proceedings of the IEEE Antennas and Propagation 
Society International Symposium, vol. 4, pp. 796-799, IEEE, Boston, Mass, USA, July 2001.

[6] R. Li, T. Wu, B. Pan, K. Lim, J. Laskar, and M. M. Tentzeris, "Equivalent-circuit analysis of a broadband printed dipole with adjusted Integrated balun and an array for base station applications," IEEE Transactions on Antennas and Propagation, vol. 57, no. 7, pp. 2180-2184, 2009.

[7] C. Sabatier, "T-dipole arrays for mobile applications," IEEE Antennas and Propagation Magazine, vol. 45, no. 6, pp. 9-26, 2003.

[8] D. Wu, Y. Yin, M. Guo, and R. Shen, "Wideband dipole antenna for 3G base stations," in Proceedings of the IEEE 2005 International Symposium on Microwave, Antenna, Propagation and EMC Technologies for Wireless Communications (MAPE'05), pp. 454-457, August 2005.

[9] H.-R. Chuang and L.-C. Kuo, "3-D FDTD design analysis of a 2.4-GHz polarization-diversity printed dipole antenna with integrated balun and polarization-switching circuit for WLAN and wireless communication applications," IEEE Transactions on Microwave Theory and Techniques, vol. 51, no. 2, pp. 374-381, 2003.
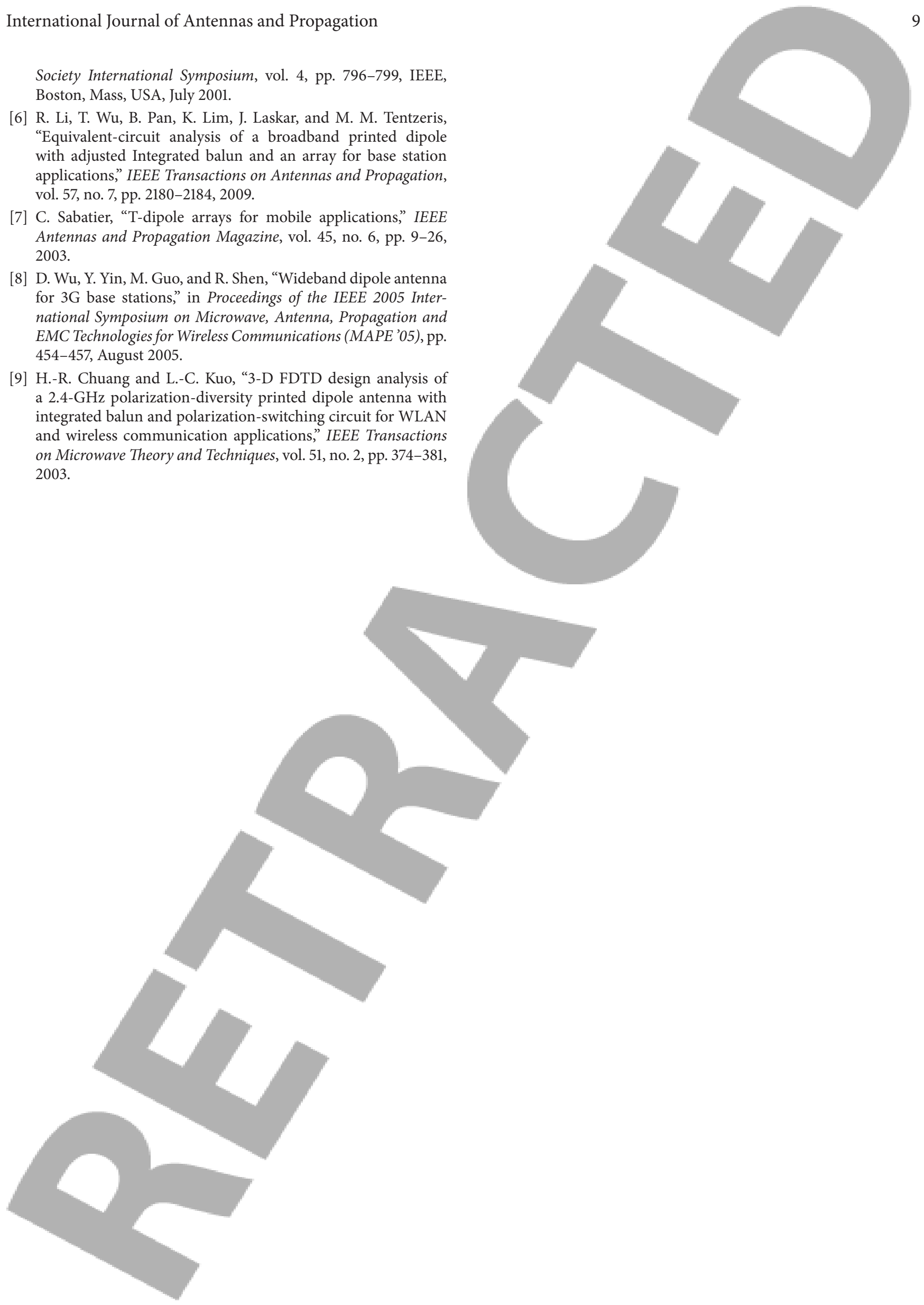